\title{
Cytosolic GAPDH as a redox-dependent regulator of energy metabolism
}

\author{
Markus Schneider ${ }^{1}$, Johannes Knuesting ${ }^{1}$, Oliver Birkholz ${ }^{2}$, Jürgen J. Heinisch ${ }^{3}$ and Renate Scheibe ${ }^{1 *}$ (D)
}

\begin{abstract}
Background: Plant cytosolic NAD-dependent glyceraldehyde-3-phosphate dehydrogenase (GapC) displays redoxdependent changes in its subcellular localizations and activity. Apart from its fundamental role in glycolysis, it also exhibits moonlighting properties. Since the exceptional redox-sensitivity of GapC has been suggested to play a crucial role in its various functions, we here studied its redox-dependent subcellular localization and the influence of the redox-state on GapC protein interactions.

Results: In mesophyll protoplasts from Arabidopsis thaliana, colocalization of GapC with mitochondria was more pronounced under reducing conditions than upon oxidative stress. In accordance, reduced GapC showed an increased affinity to the mitochondrial voltage-dependent anion-selective channel (VDAC) compared to the oxidized one. On the other hand, nuclear localization of GapC was increased under oxidizing conditions. The essential role of the catalytic cysteine for nuclear translocation was shown by using the corresponding cysteine mutants. Furthermore, interaction of GapC with the thioredoxin Trx-h3 as a candidate to revert the redox-modifications, occurred in the nucleus of oxidized protoplasts. In a yeast complementation assay, we could demonstrate that the plant-specific non-phosphorylating glyceraldehyde 3-P dehydrogenase (GapN) can substitute for glucose 6-P dehydrogenase to generate NADPH for re-reduction of the Trx system and ROS defense.

Conclusions: The preferred association of reduced, glycolytically active GapC with VDAC suggests a substratechanneling metabolon at the mitochondrial surface for efficient energy generation. Increased occurrence of oxidized $\mathrm{GapC}$ in the nucleus points to a function in signal transduction and gene expression. Furthermore, the interaction of GapC with Trx-h3 in the nucleus indicates reversal of the oxidative cysteine modification after re-establishment of cellular homeostasis. Both, energy metabolism and signal transfer for long-term adjustment and protection from redoximbalances are mediated by the various functions of GapC. The molecular properties of GapC as a redox-switch are key to its multiple roles in orchestrating energy metabolism.
\end{abstract}

Keywords: Redox, Metabolism, GAPDH, VDAC, Thioredoxin, Mitochondria, Nucleus, Glycolysis, Metabolon, GapN

\section{Background}

Pathways of plant metabolism that generate energy equivalents both from light and from substrate in the various cellular compartments must be permanently adjusted to changing environmental factors and metabolic requirements. The electron-transport chains in chloroplasts and mitochondria are major sources of redox-imbalances and radical formation under stress. Signals arising from such imbalances are sensed and transferred to the nucleus.

\footnotetext{
* Correspondence: scheibe@biologie.uni-osnabrueck.de

${ }^{1}$ Division of Plant Physiology, Department of Biology and Chemistry,

Osnabrück University, Barbarastr. 11, 49076 Osnabrück, Germany

Full list of author information is available at the end of the article
}

Altered gene expression will then help to maintain homeostasis of metabolic fluxes and cellular redox-state [1].

NAD-dependent glyceraldehyde-3-phosphate dehydrogenase (GAPDH; E.C. 1.2.1.12) is a highly conserved glycolytic enzyme in all kingdoms of life. Several non-glycolytic functions of GAPDH have also been observed, classifying this enzyme as prototypical example for moonlighting (for reviews see [2-6]:). In A. thaliana, GapC1 (At3g04120) and GapC2 (At1g13440) are the GAPDH isoforms residing in the cytosol. We previously characterized redox-dependent cysteine modifications of GapC, namely $S$-glutathionylation and $S$-nitrosylation, which result in inactivation of the enzymes [7]. In a yeast two-hybrid screen, VDAC was identified as an

(c) The Author(s). 2018 Open Access This article is distributed under the terms of the Creative Commons Attribution 4.0 International License (http://creativecommons.org/licenses/by/4.0/), which permits unrestricted use, distribution, and 
interaction partner of GapC [8]. Moreover, a fraction of GapC was shown to be localized to the nucleus of Arabidopsis mesophyll protoplasts [7, 9-11], and associated with the outer mitochondrial membrane (OMM) and the cytoskeleton [9]. S-sulfhydrylation of GapC has been observed to also result in nuclear localization of the modified protein [12].

GAPDH is most sensitive towards oxidation at its catalytic cysteine residue [13-15], and thus represents an initial redox sensor and a hub to induce the various responses that are required to maintain redox-homeostasis $[15,16]$. Glutathionylation and nitrosylation of GapC were found in large-scale proteomic approaches, both in plants and animals [17-20]. GAPDH was also suggested to act as an $\mathrm{H}_{2} \mathrm{O}_{2}$ sensor by triggering the protective oxidative stress response and re-establishment of cellular homeostasis [21]. Modification of the catalytic cysteine of GapC, only occurring in the absence of the substrate, leads to reversible or irreversible inactivation of the enzyme, depending on the oxidant, as demonstrated in vitro [7]. In addition to the regulation of enzyme activities, such modifications are assumed to affect signaling cascades and other moonlighting functions.

Trx and NADPH-thioredoxin reductases (NTR) are universal mediators of cellular redox-modifications [22, 23]. For continuous re-reduction, reducing equivalents can be provided by NADPH-dependent reductases, e.g., glucose-6-P dehydrogenase (G6PDH) or the plant-specific irreversible non-phosphorylating glyceraldehyde-3 phosphate reductase (GapN; EC 1.2.1.9) [24].

In this study, we focused on the redox-dependent interactions of GapC with VDAC as a central regulator of the metabolic flux across the OMM $[25,26]$, as well as the nuclear translocation of $\mathrm{GapC}$, and its interaction with $\operatorname{Trx}-h 3$ as a candidate for catalyzing the reversal of the transient oxidative modification [27]. We used both, in vitro approaches such as reflectance interferometry (RIf) as well as in vivo experiments by expressing fluorescent fusion proteins in isolated mesophyll protoplasts and by heterologous enzyme complementation in yeast. Oxidants and reductants, as well as cysteine mutants of GapC, were used to analyze the redox-dependent localization of GapC1 and GapC2 in the different cellular subcompartments and their interactions with VDAC3 and Trx-h3. The cellular localizations and interactions found under reducing and under oxidizing conditions might help to unravel the various functions of GapC in more detail.

\section{Methods}

\section{Isolation and transient transformation of Arabidopsis protoplasts}

Subcellular localization and interaction studies with fluorescent fusion proteins of GapC1, GapC2 and Trx- $h 3$ were performed in mesophyll protoplasts isolated from leaves of 4-week-old wild-type $A$. thaliana plants grown under short-day conditions. Isolation and transformation of protoplasts were performed according to [28], with modifications described in [29].

\section{Imaging of fluorescent fusion proteins in transiently transformed protoplasts}

For GapC-localization studies, SmaI/XbaI fragments encoding C-terminal mEGFP-fusions of GapC1 and GapC2 were cloned into the binary transformation vector pBAR-35S. To express the fusion proteins in vivo, mesophyll protoplasts were transiently transformed with the pBAR-35S-mEGFP constructs and incubated for $16 \mathrm{~h}$ at $22^{\circ} \mathrm{C}$. Plant mitochondria were visualized by staining with 500 nM MitoTracker ${ }^{\circ}$ Red FM (Thermo Fisher Scientific, Waltham, USA). The protoplasts were imaged using a confocal laser scanning microscope (cLSM) 510META (Carl Zeiss, Göttingen, Germany). The mEGFP fluorescence and chlorophyll autofluorescence were excited at $488 \mathrm{~nm}$. The mEGFP emission was detected at 500$530 \mathrm{~nm}$, chlorophyll autofluorescence was monitored in the range of $650-700 \mathrm{~nm}$.

To quantify the nuclear localization of GapC1 and GapC2 fluorescent fusions, the basic leucine zipper protein bZIP63 was used as a nuclear marker protein. The bZIP63 cDNA from Arabidopsis was cloned as a SmaI/ $\mathrm{XbaI}$ fragment into the binary vector pBAR-35S to yield a C-terminal mCherry fusion. The resulting plasmid was co-transformed with constructs encoding GapC-mEGFP fusion proteins, as indicated. The mCherry fluorescence was detected by excitation at $585 \mathrm{~nm}$ and emission at 600-620 nm. The mEGFP signal was determined in the cytosol and the nucleus for at least 50 protoplasts in three independent experiments as described above. The fluorescence intensities of the cytosolic and nuclear mEGFP signals were calculated as the ratio of each individual signal to the sum of both.

For split-YFP experiments, the cDNA sequences of the Arabidopsis proteins GapC1, GapC2 and Trx- $h 3$ were cloned as BamHI/KpnI fragments into the vectors pUC-SPYNE or pUC-SPYCE [30] to generate C-terminal fusions with the $\mathrm{N}$ - or C-terminal part of YFP, respectively. bZIP63-mCherry was used as a nuclear marker as described above. To express the fusion proteins in vivo, mesophyll protoplasts were transiently co-transformed with the pBAR-35S constructs and incubated for $16 \mathrm{~h}$ at $22{ }^{\circ} \mathrm{C}$. For detection, complemented YFP was excited at $514 \mathrm{~nm}$, and emission was monitored at $525-540 \mathrm{~nm}$.

For each experiment, cLSM raw data were processed with the Fiji software system [31].

\section{Treatments of isolated protoplasts with redox-reagents} To analyze localization and interactions of the various proteins under different redox conditions, transformed 
Arabidopsis mesophyll protoplasts were treated with $10 \mathrm{mM}$ DTT, $50 \mu \mathrm{M}$ GSNO or $0.2 \mathrm{mM} \mathrm{H}_{2} \mathrm{O}_{2}$ by incubation at $22{ }^{\circ} \mathrm{C}$ for $40 \mathrm{~min}$ prior to cLSM analysis. In preliminary experiments, intactness of the protoplasts after the treatments was checked.

\section{Expression and purification of recombinant GapC and Trx-h3 from $A$. thaliana}

Expression and purification of the recombinant GapC and Trx- $h 3$ proteins from $A$. thaliana were performed as previously described [7]. In the case of $\operatorname{Trx}-h 3$, the protein was stored in $20 \mathrm{mM}$ Tris- $\mathrm{HCl}(\mathrm{pH}$ 8.0) containing $150 \mathrm{mM} \mathrm{NaCl}$. GapC was stored in $50 \mathrm{mM}$ Tris- $\mathrm{HCl}$ (pH 7.8), $5 \mathrm{mM}$ EDTA, $150 \mathrm{mM} \mathrm{KCl,} 2 \mathrm{mM}$ DTT, $140 \mu \mathrm{M}$ NAD, 50\% glycerol, and desalted before use.

\section{Expression, refolding, purification and reconstitution of recombinant VDAC3 from $A$. thaliana}

Overexpression, refolding and purification of Arabidopsis VDAC3 was performed according to [32,33] with modifications. VDAC3 was overexpressed using the cold-shock expression system described by [34]. The Arabidopsis VDAC3 cDNA was cloned into the pCold I DNA vector (Takara Bio Europe/Clontech, Saint-Germain-en-Laye, France) using SacI and XbaI. The E. coli mutant strain

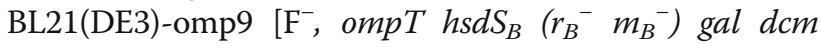
(DE3) $\triangle l a m B$ ompF::Tn5 $\triangle$ ompA $\triangle$ ompC $\triangle o m p N:: \Omega][35$, 36] was transformed with the pCold I DNA-AtVDAC3 vector. Liquid LB medium (containing $100 \mu \mathrm{g} \mathrm{m}{ }^{-1}$ ampicillin) was inoculated with a starter culture. Cells were cultivated at $37{ }^{\circ} \mathrm{C}$ under shaking at $200 \mathrm{rpm}$. After reaching an $\mathrm{OD}_{600}$ of $0.8-1.0$ the cultures were incubated on ice for $30 \mathrm{~min}$. Protein expression was induced by the addition of isopropyl- $\beta$-D-thiogalactopyranoside $(1 \mathrm{mM})$ and transfer of the cultures to $15{ }^{\circ} \mathrm{C}$. The cells were incubated at $15{ }^{\circ} \mathrm{C}$ and $200 \mathrm{rpm}$ for further $24 \mathrm{~h}$ and finally harvested by centrifugation $\left(5000 \mathrm{xg}, 20 \mathrm{~min}, 4{ }^{\circ} \mathrm{C}\right)$. The cell pellet was shock-frozen in liquid nitrogen and stored at $-80{ }^{\circ} \mathrm{C}$. For protein purification, the cells were thawed, emerged in resuspension buffer $(50 \mathrm{mM}$ Tris- $\mathrm{HCl}, \mathrm{pH} 8.0$, $100 \mathrm{mM} \mathrm{NaCl}, 0.1 \mathrm{mM}$ EDTA) and disrupted by ultrasonication (Vibracell, Fisher Scientific, Illkirch, France). The VDAC3-containing inclusion bodies were collected by centrifugation $\left(25000 \mathrm{xg}, 30 \mathrm{~min}, 4{ }^{\circ} \mathrm{C}\right)$, and washed three times with detergent-containing washing buffer $(50 \mathrm{mM}$ Tris- $\mathrm{HCl}, \mathrm{pH}$ 8.0, $100 \mathrm{mM} \mathrm{NaCl}, 10 \mathrm{mM}$ EDTA, 2.5\% ( $v /$ v) Triton $X-100$ ), followed by three washing steps using detergent-free washing buffer $(50 \mathrm{mM}$ Tris- $\mathrm{HCl}, \mathrm{pH}$ 8.0, $100 \mathrm{mM} \mathrm{NaCl}$ ). The inclusion bodies were treated with denaturation buffer $\left(25 \mathrm{mM} \mathrm{NaH} \mathrm{PO}_{4} / \mathrm{Na}_{2} \mathrm{HPO}_{4}, \mathrm{pH} 7.0\right.$, $100 \mathrm{mM} \mathrm{NaCl}, 1 \mathrm{mM}$ EDTA, $10 \mathrm{mM}$ DTT, $6 \mathrm{M}$ guanidinium chloride). A 10-fold dilution of the guanidinium chloride was achieved by drop-wise addition to refolding buffer I (25 mM NaH $\mathrm{PO}_{4} / \mathrm{Na}_{2} \mathrm{HPO}_{4}, \mathrm{pH} 7.0,100 \mathrm{mM}$
$\mathrm{NaCl}, 1 \mathrm{mM}$ EDTA, 2.22\% (v/v) lauryl-dimethyl-amine oxide (LDAO)). This mixture was stirred for $18 \mathrm{~h}$ at $4{ }^{\circ} \mathrm{C}$. A further 10-fold dilution of the guanidinium chloride by drop-wise addition to refolding buffer II $(25 \mathrm{mM}$ $\mathrm{NaH}_{2} \mathrm{PO}_{4} / \mathrm{Na}_{2} \mathrm{HPO}_{4}$, pH 7.0, $10 \mathrm{mM} \mathrm{NaCl}, 1 \mathrm{mM}$ EDTA, $0.1 \%(\mathrm{v} / \mathrm{v}) \mathrm{LDAO}$ ) and stirring for $18 \mathrm{~h}$ at $4{ }^{\circ} \mathrm{C}$ followed this step.. Insoluble material was removed by passage through a $0.22-\mu \mathrm{m}$ filter. For cation-exchange chromatography, the sample was loaded onto a pre-equilibrated Fractogel $^{\circ}$ EMD SE Hicap (M) (Merck, Darmstadt, Germany) cation-exchange column connected to an ÄKTAprime plus chromatography system (GE Healthcare, Munich, Germany). Elution of the refolded VDAC3 proteins was achieved using a linear gradient from $10 \mathrm{mM}$ $\mathrm{NaCl}$ to $1 \mathrm{M} \mathrm{NaCl}$ in the elution buffer $(25 \mathrm{mM}$ $\mathrm{NaH}_{2} \mathrm{PO}_{4} / \mathrm{Na}_{2} \mathrm{HPO}_{4}$, pH 8.0, $10 \mathrm{mM} \mathrm{NaCl}, 1$ mM EDTA, $1 \mathrm{mM}$ DTT, 0.1\% ( $v / \mathrm{v})$ LDAO). The VDAC3-containing fractions were pooled and concentrated using a $10-\mathrm{kDa}$ Amicon concentrator (Merck, Darmstadt, Germany). Size-exclusion chromatography was performed by loading the refolded VDAC3 onto pre-equilibrated (10 mM Tris-HCl, pH 8.0, $100 \mathrm{mM} \mathrm{NaCl}, 0.05 \%$ LDAO) Superose ${ }^{\mathrm{Tm}}$ 12 10/300 GL column (GE Healthcare, Munich, Germany), and the elution profiles were recorded at $280 \mathrm{~nm}$. The protein-containing fractions concentrated using a 10-kDa Amicon concentrator (Merck, Darmstadt, Germany).

\section{Preparation of VDAC3-containing proteoliposomes}

For RIf experiments, the recombinant VDAC3 was reconstituted into 1,2-dioleoyl-sn-glycero-3-phosphocholine (DOPC) liposomes in a molar ratio of 1:1000 (protein:lipid). The VDAC3- containing proteoliposomes were formed by detergent extraction in the presence of heptakis-(2,6-di-O-methyl)- $\beta$-cyclodextrin $(\beta-\mathrm{CD})$ (Sigma) [37]. A mixture of $5 \mathrm{mM}$ of DOPC and $20 \mathrm{mM}$ Triton X-100 in HBS buffer (20 mM Hepes- $\mathrm{KOH}, \mathrm{pH} 7.4,300 \mathrm{mM} \mathrm{NaCl}$ ) and LDAO-solubilized recombinant VDAC3 was prepared before a 2 -fold excess of $\beta$-CD over the detergent was added. The mixture was incubated for $5 \mathrm{~min}$ at room temperature and diluted in HBS buffer.

\section{Reflectance interferometry (RIf)}

Poly-L-lysine (PLL - PEG-AC) modification of glass coverslips required for RIf was performed as described by [38, 39]. All measurements were conducted in a home-built setup as described in detail by [40]. The polymer-supported membrane was formed by injection of the VDAC3containing proteoliposomes followed by rinsing with HBS buffer. After formation of the polymer-supported membrane, pre-treated recombinant $\mathrm{GapC}$ was injected. For each $\mathrm{GapC}$ injection, the surface was regenerated by two washing steps with $0.1 \%(v / v)$ Triton X-100. Extraction of pseudo-first order kinetic constants was 
performed by separately fitting dissociation and association phases using BIAevaluation 3.1 software (GE Healthcare, Little Chalfont, UK).

Silanization of RIf transducer chips with (3-glycidyl oxypropyl)-trimethoxysilane, and subsequent reaction with bis-amino-PEG with an average molecular mass of 2,000 Da was carried out as previously described [41]. Terminal amines were converted into carboxylates by incubation with $1 \mathrm{M}$ succinic anhydride in $20 \mathrm{mM}$ Hepes-KOH, pH 7.0, before the surface was NHSactivated by incubation with equimolar amounts of N-hydroxysuccinimide and 1-ethyl-3-(3-dimethylaminopropyl) carbodiimide (each $500 \mathrm{mM}$ in dimethylformamide (DMF)) for $30 \mathrm{~min}$. After washing with DMF, recombinant $\mathrm{GapC} 1$ at $\mu$ molar concentrations was added for immobilization. After $15 \mathrm{~min}$ at room temperature, excess protein was removed by rinsing with HBS buffer.

\section{Yeast strains and constructs for heterologous expression of the GapN encoding gene}

To study phenotypic rescue in yeast, a derivative of the strain HD56-5A [42], was employed which carries a deletion of the sole $Z W F 1$ gene encoding glucose- 6 phosphate dehydrogenase. To obtain this deletion, the one-step gene deletion method using a PCR product obtained from the template pUG6 [43] with the primer pair 16.235/16.236 (Additional file 1: Table S1) was applied to the homozygous diploid strain DHD5 [44]. Sporulation and tetrad analysis yielded the haploid segregant HOD269-1C (MATa ura3-52 his3-11, 15 leu23,112 zwf1::kanMX), which was used as a recipient strain for transformation with different plasmids as indicated in the results section. As a basis for heterologous gene expression, the vector pJJH2064 was used, which carries an optimized yeast PFK2 promoter on a 576 bp EcoRI/ BamHI DNA fragment obtained from custom-made string synthesis (Geneart, Thermo Fisher Scientific, Waltham, USA) introduced into the CEN/ARS plasmid YCplac33 [45]. The promoter sequence was chosen according to previous analyses indicating that it allows for full and constitutive expression of downstream genes [46]. Point mutations were inserted as required to eliminate internal restriction sites from the native promoter sequence. String synthesis was also employed to obtain the sequence of the Arabidopsis gene encoding GapN adapted to the yeast codon usage and flanked by a BamHI restriction site immediately preceding the ATG translation start codon and a HindIII site following the respective translation stop codons. The gene was then cloned as BamHI/HindIII-fragment into pJJH2064, which was introduced into the yeast recipient strain by selecting for uracil prototrophy. As controls, the vector not carrying an insertion, YCplac33 carrying the native yeast $Z W F 1$ gene including its flanking regions obtained by PCR with the primer pair 16.232/16.233 (Additional file 1: Table S1) from genomic yeast DNA cloned as a SacI/SalI fragment, or the yeast ZWF1 gene introduced into pJJH2064 under the control of the PFK2 promoter as a BamHI/HindIII fragment obtained with the oligonucleotide pair 16.234/16.233 (Additional file 1: Table S1) from genomic yeast DNA were used.

To assess the capacity of the different constructs to rescue the oxidative-stress sensitive phenotype of the yeast $z w f 1$ deletion strain, transformants were grown overnight in $3 \mathrm{ml}$ of synthetic complete medium lacking uracil (SCura; $2 \%$ glucose, $0.67 \%$ yeast nitrogen base with ammonium sulfate, supplemented with standard amino acids and adenine) according to [47], diluted to an $\mathrm{OD}_{600}$ of approximately 0.1 in fresh medium and grown for another 4-6 h. Cells were again diluted to an $\mathrm{OD}_{600}$ of 0.1 and used to prepare four 10-fold serial dilutions. Five $\mu \mathrm{l}$ of each dilution was spotted on SCura plates containing $1.5 \%$ agar with $\mathrm{H}_{2} \mathrm{O}_{2}$ added at the concentrations as indicated. Growth was recorded by scanning the plates after 3 days of incubation at $30^{\circ} \mathrm{C}$.

For determination of specific enzyme activities, crude extracts were prepared from $20 \mathrm{ml}$ of yeast cells growing exponentially in SCura at $30{ }^{\circ} \mathrm{C}$. Cells were harvested, washed with $50 \mathrm{mM}$ Tris- $\mathrm{HCl}, \mathrm{pH} 7.5$, and broken with glass beads as described previously [48]. Protein concentrations in crude extracts were determined with the Microbiuret method [49] using bovine serum albumin as a standard. G6PDH activity was measured by following NADP reduction at $340 \mathrm{~nm}$ after addition of $2.5 \mathrm{mM}$ glucose 6-phosphate as the substrate to the reaction mixture, which consisted of $50 \mathrm{mM}$ Tris- $\mathrm{HCl}, \mathrm{pH} 7.5$, and $0.4 \mathrm{mM}$ NADP and appropriate amounts of crude extract. Similarly, GapN activity was determined in the same buffer by recording NADP reduction. To the latter, $0.5 \mathrm{U} / \mathrm{ml}$ aldolase was added as an ancillary enzyme, and the reaction was started with $2.5 \mathrm{mM}$ fructose 1,6-bisphosphate.

\section{Results}

\section{Association of GapC1 with mitochondria under different redox conditions}

The GapC protein was previously found to associate with plant mitochondria $[50,51]$. However, the role of this interaction remained unclear. Since metabolic fluxes and the cellular redox-state are closely related, we first analyzed the redox-dependence of the co-localization between $\mathrm{GapC}$ and mitochondria. For this purpose, isolated Arabidopsis mesophyll protoplasts were transformed with a GapC1-mEGFP fusion construct under the control of the S35-promoter. Simultaneously, mitochondria were stained with MitoTracker ${ }^{\bullet}$ Red FM to detect colocalizations. To assess the influence of the different redox conditions, protoplasts were pretreated 
with $0.2 \mathrm{mM} \mathrm{H}_{2} \mathrm{O}_{2}$ or $10 \mathrm{mM}$ DTT. Fluorescent signals resulting from the fusion-proteins were detectable in the cytosol under reducing and oxidizing conditions (Fig. 1). Colocalization of GapC1-mEGFP with mitochondria was also found under both conditions, as indicated by white spots in the merged images. However, GapC1 was found to colocalize more frequently with mitochondria in a reducing environment, after DTT treatment of the protoplasts, than in the oxidized sample $\left(\mathrm{H}_{2} \mathrm{O}_{2}\right.$ treatment) (Fig. 1). These findings suggest that the GapC1 protein is predominantly recruited to the OMM under reducing conditions, in contrast to its presumed oxidized state. For quantification of this effect, we chose an in vitro approach (see below).

\section{Binding constants of GapC1 interacting with VDAC3 under reducing and oxidizing conditions}

In earlier studies, an association of the GapC protein with the OMM via VDAC3 had been demonstrated in a split-YFP assay with mesophyll protoplasts kept under reducing conditions [9]. In the light of the redoxdependent GapC localization to the OMM (Fig. 1), we decided to determine the binding kinetics of GapC1 to the mitochondrial VDAC3 under reducing and oxidizing conditions by RIf. In this approach, recombinant VDAC had been refolded and incorporated into a lipid bilayer, thus representing the native state on a solid support membrane. Binding and dissociation of $\mathrm{GapC} 1$ to reconstituted VDAC3 was recorded in a flow chamber by measuring changes in white-light interference in a massand protein-sensitive manner (Fig. 2a, Additional file 2: Figure S1). Different amounts of reduced (pretreatment with $2 \mathrm{mM}$ DTT) and oxidized (pretreatment with
$0.5 \mathrm{mM} \mathrm{H} \mathrm{H}_{2} \mathrm{O}_{2}+0.5 \mathrm{mM}$ GSH) GapC1 protein were injected to determine the redox-dependent effects on the strength of the interaction with the VDAC3 resident in a lipid bilayer (Fig. 2a). Binding properties of GapC1 to a protein-free lipid membrane served as a negative control. Thus, the equilibrium constants $\left(K_{\mathrm{D}}\right)$ for the interaction of reduced and oxidized GapC1 with VDAC3 could be determined. The $K_{\mathrm{D}}$ value of oxidized GapC1 ranged at $556.3 \pm 69.9 \mathrm{nM}$, while a lower $K_{\mathrm{D}}$ value of $236.0 \pm 19.8$ nM was obtained for reduced GapC1 (Fig. 2b, Additional file 2: Figure S1). This indicates a twofold increase of the affinity for VDAC3 of reduced GapC1 compared to the oxidized form.

\section{Nuclear localization of GapC isoforms and their cysteine mutants under different redox conditions}

Besides their interaction with VDACs at the mitochondrial surface, GapC isoforms can also translocate into the nucleus. Therefore, GapC-mEGFP fusion proteins were expressed in Arabidopsis mesophyll protoplasts to follow their subcellular distribution under different redox-conditions. For this purpose, the protoplasts were pretreated with $10 \mathrm{mM}$ DTT or $0.2 \mathrm{mM} \mathrm{H}_{2} \mathrm{O}_{2}$, before analysis by cLSM. Both, GapC1- and GapC2-mEGFP fusion proteins showed fluorescent signals in the cytosol, but also in the nucleus. Nuclear localization was confirmed by the overlap with the fluorescent signals of the nuclear bZip63-mCherry marker (Fig. 3a, b). In protoplasts subjected to $10 \mathrm{mM}$ DTT, the fluorescent signals appeared predominantly in the cytosol, while pretreatment of the protoplasts with $0.2 \mathrm{mM} \mathrm{H}_{2} \mathrm{O}_{2}$ resulted in an increased nuclear localization of GapC1-mEGFP and GapC2-mEGFP fusion proteins (Fig. 3a, b).

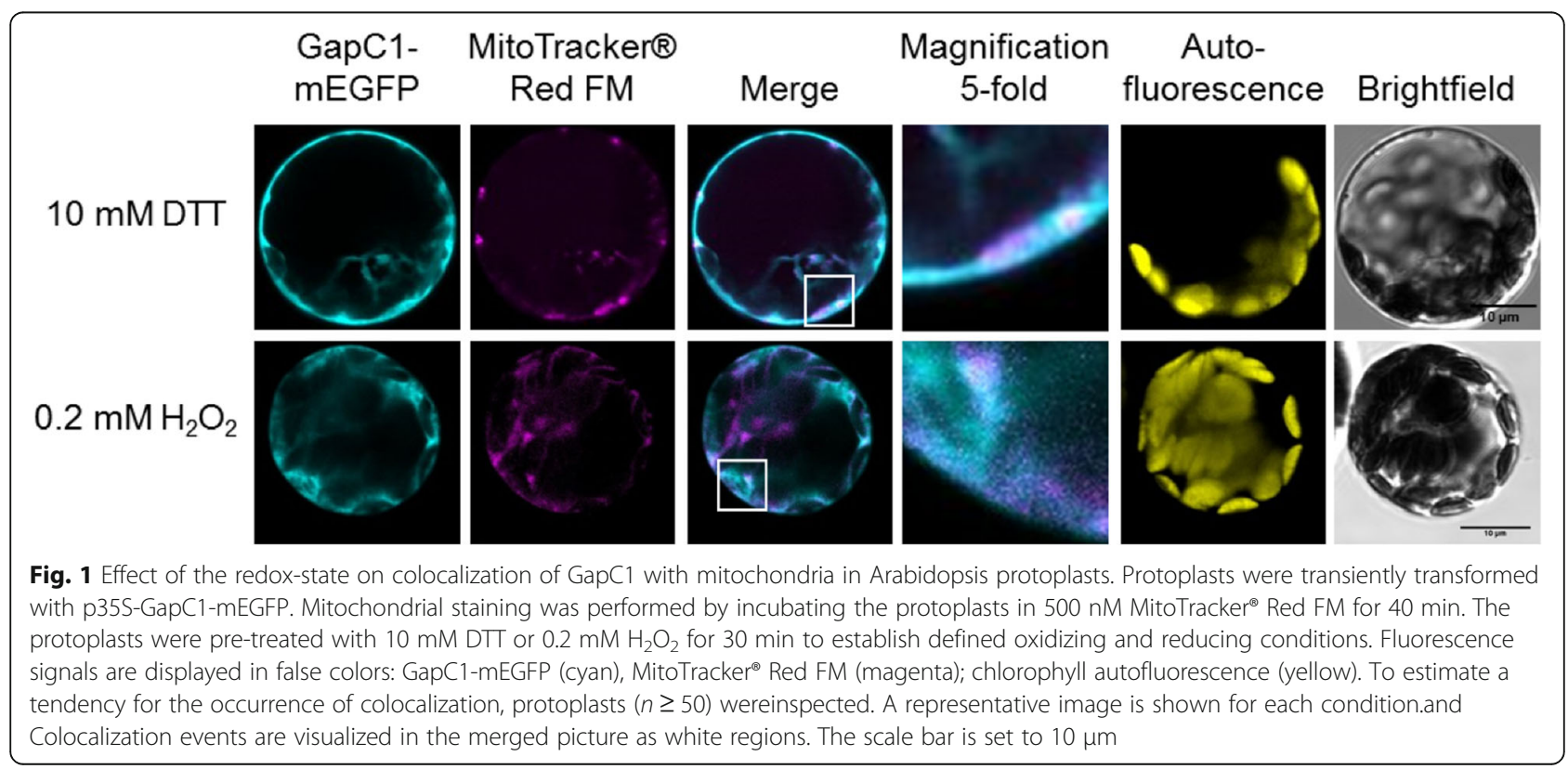



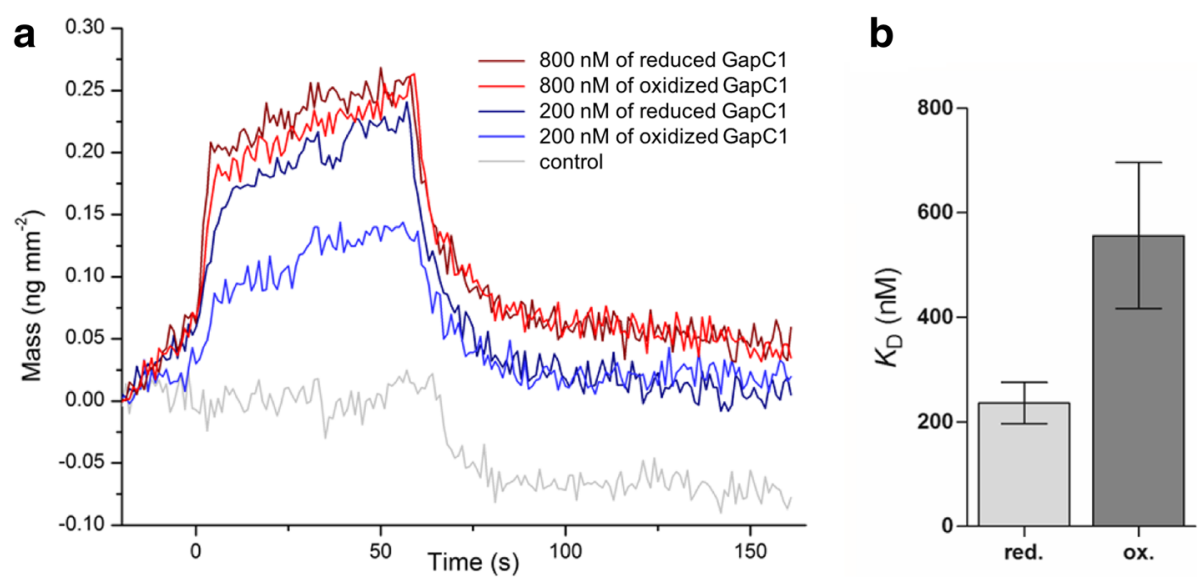

Fig. 2 Redox-dependent binding of GapC1 to VDAC3. a Association and dissociation behavior of reduced and oxidized recombinant GapC1 added to bilayer-incorporated recombinant VDAC3 at the indicated concentrations is shown as original traces. For reduction, samples were pre-treated with $2 \mathrm{mM}$ DT, for oxidation with $0.5 \mathrm{mM} \mathrm{H}_{2} \mathrm{O}_{2}+0.5 \mathrm{mM} \mathrm{GSH}$. b Equilibrium dissociation constants ( $K_{\mathrm{D}}$ ) of pre-treated GapC1 binding to VDAC3 were obtained as described in Material \& Methods. Error bars represent SD, $p$-value by Students t-test $p \leq 0.005$

For quantification of the redox-dependent localization of GapC1/2, single and double Cys mutants of GapC1 and $\mathrm{GapC} 2$ were also included to determine the influence of presence and redox-state of the key cysteine residues on the nuclear localization of GapC. At least 50 protoplasts were analyzed for subcellular localization of each case. In accordance with the previous observations, wild-type $\mathrm{GapC} 1$ and $\mathrm{GapC} 2$ showed a significant increase of nuclear localization under oxidizing conditions compared to the reducing conditions (Fig. 4a, b). GSNO was included in this experiment, since ROS can initiate NO formation in vivo leading to the formation of GSNO by nitrosylation of a small portion of the GSH pool. Both thiol oxidants, GSNO and $\mathrm{H}_{2} \mathrm{O}_{2}$, led to similar distributions of the GapC isoforms between cytosol and nucleus. In contrast, protoplasts carrying GapC with either the C156S mutation or the C156S/C160S-double mutation did not respond with an increased translocation of the GapC isoforms to the nucleus upon oxidation. It should be mentioned that under reducing conditions all mutant enzymes tended to be more abundant in the nucleus than their wild-type counterparts. Taken together, these findings suggest that the catalytic cysteine residue C156 is required for sensing the cellular redox state. Its oxidative modification is required to initiate nuclear translocation of the cytosolic GapC isoforms.

\section{Interaction of GapC with Trx-h3}

GapC has been found as a target of Trx, which can convert the enzyme back into its reduced state [27, 52-54]. Trx, in turn, would be re-reduced by NADPH as mediated by the NTR system [23]. To fulfill its function in vivo, Trx would have to interact with GapC. To test this assumption, split-YFP assays were applied to isolated Arabidopsis mesophyll protoplasts subjected to various redox conditions. The protoplasts were transformed with constructs for fusion proteins of the N-terminal half of YFP $\left(\mathrm{YFP}_{\mathrm{NE}}\right.$ ) fused to either GapC1 or GapC2 and the C-terminal half $\left(\mathrm{YFP}_{\mathrm{CE}}\right)$ fused to Trx- $h 3$. The bZip63mCherry nuclear marker was used as a control. Treatment of the transformed mesophyll protoplasts with $20 \mathrm{mM}$ DTT resulted in the interaction of Trx-h3-YFP with GapC1-YFP $\mathrm{NE}_{\mathrm{NE}}$ and GapC2-YFP $\mathrm{NE}$, respectively, as indicated by the YFP fluorescence in the cytosol (Fig. 5a, b). Treatment with $0.2 \mathrm{mM} \mathrm{H}_{2} \mathrm{O}_{2}$ or $0.05 \mathrm{mM}$ GSNO to establish an oxidative environment led to enhancement of the nuclear fluorescence signal, generated by the interaction of Trx-h3 with either GapC1 or GapC2 in the nucleus. Nevertheless, a significant portion of these interactions could still be detected in the cytosol under these conditions (Fig. 5a, b). This result indicates that Trx- $h 3$ might be able to remove the oxidative modifications at the active-site cysteine $\mathrm{C} 156$ of GapC, both in the cytosol and in the nucleus.

The interaction of GapC with Trx-h3 was further analyzed in vitro by RIf. Association and dissociation of $\operatorname{Trx}-h 3$ to the immobilized GapC1 protein was recorded at different concentrations of Trx-h3 (Fig. 6). Due to the transient interactions, the $K_{\mathrm{D}}$ had to be determined by the equilibrium binding signals using a Scatchard plot and yielded a value of $40 \mu \mathrm{M}$ (Additional file 3: Figure S2). In contrast, immobilization of the unrelated yellow fluorescent protein mCitrine to the surface did not lead to any significant association of Trx-h3.

\section{Complementation of a yeast zwf1 deletion strain lacking G6PDH by expression of plant cytosolic GapN}

The reduced cofactor NADPH is required to recover cells from oxidative stress. It provides electrons for re-reduction of oxidized glutathione (GSSG) and GSNO, 


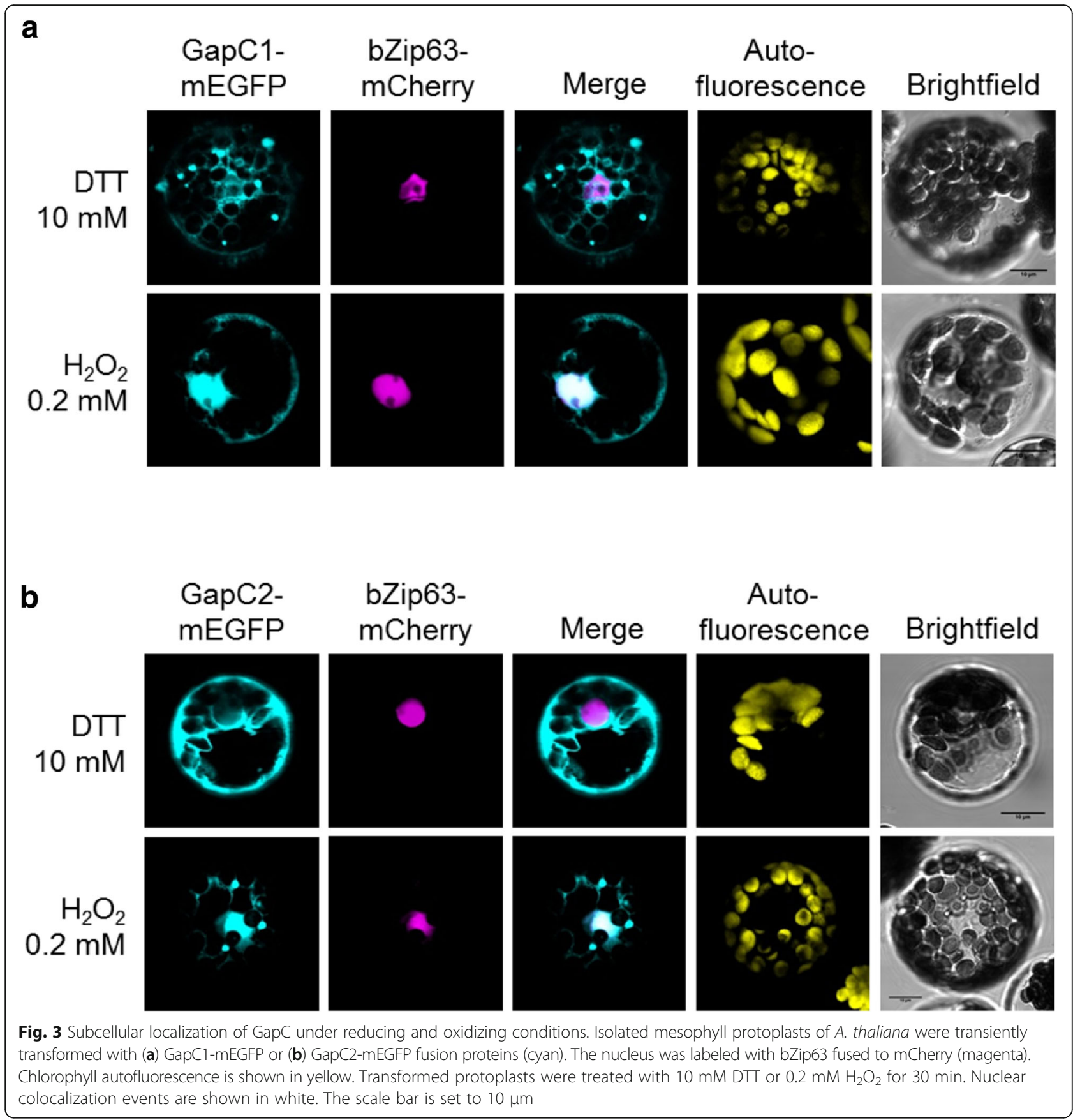

and the reversal of oxidative modifications at GapC by Trx and NTR [22]. Any enzyme or signaling activity of GapC affected by its oxidation, or that of its orthologs from other organisms, can thus be reverted when the cells recover from the stress situation, and the metabolic flux can be switched back to active glycolysis. The oxidative branch of the pentose pathway, with G6PDH as a key enzyme, generates NADPH in all organisms, in human and in yeast cells represented by single isoforms and in plants by six isoforms [55]. In addition, plants and bacteria possess a highly stable GapN [54, 56], which is a prime candidate for additional NADPH production in stressful conditions.

To study this putative function of GapN in a system devoid of background activity, we constructed a yeast zwf1 deletion mutant, which lacks its endogenous G6PDH $[57,58]$. As a positive control, we employed a similar construct carrying the native $Z W F 1$ gene from $S$. cerevisiae. All genes were expressed from a single-copy $C E N / A R S$ plasmid under the control of the constitutive $P K F 2$ promoter, in a derivative of a system previously employed for the heterologous expression of PFK genes 


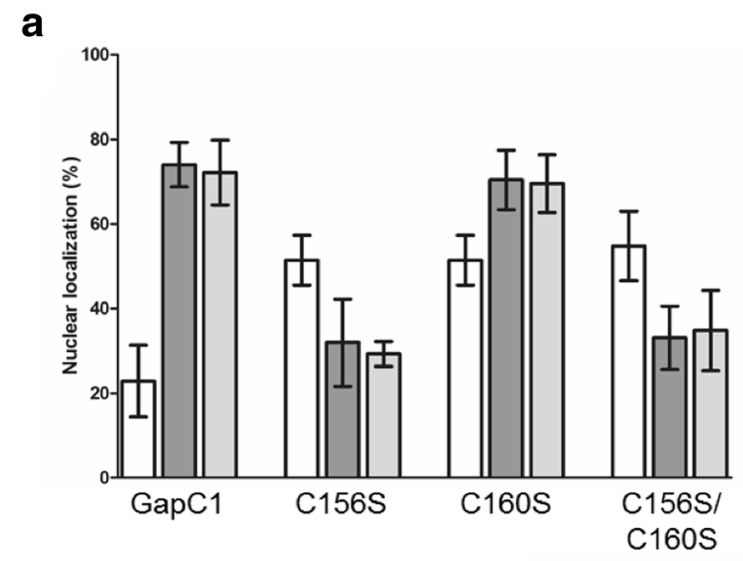

b

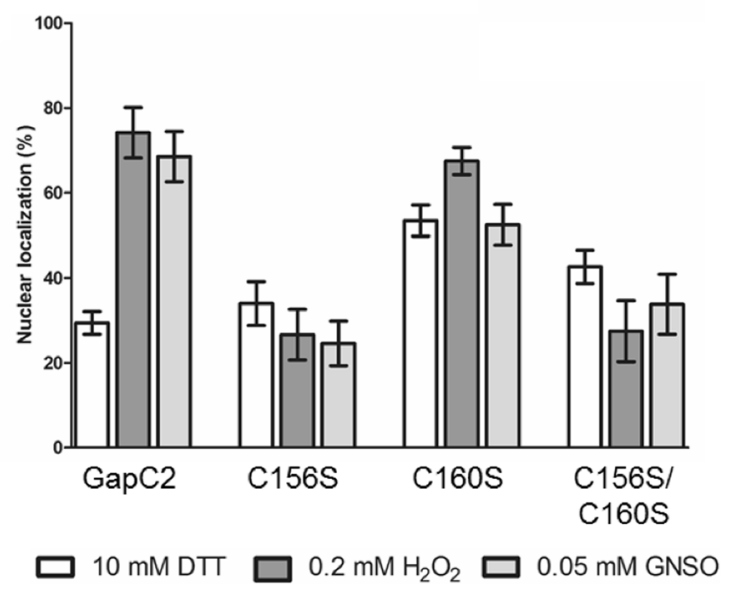

Fig. 4 Redox-dependent distribution of GapC between cytosol and nucleus. For quantification of nuclear localization, mesophyll protoplasts were transiently transformed with GapC-mEGFP fusions of the isoforms GapC1 (a), and GapC2 (b), and their corresponding single (C156S and C160S) and double (C156S/C160S) cysteine mutants. The subcellular localization was determined after the treatment with different redox reagents (10 mM DTT; $0.2 \mathrm{mM} \mathrm{H}_{2} \mathrm{O}_{2}$ or $0.05 \mathrm{mM} \mathrm{GSNO}$ ). ( $\mathrm{n} \geq 50$ analyzed protoplasts. The sum of cytosolic and nuclear mEGFP-signal corresponds to $100 \%$ for each experiment; mean \pm SD)

from patients with Tarui's disease in yeast [59] introduced into the $z w f 1$ deletion. Drop-dilution assays of the different transformants on plates containing $\mathrm{H}_{2} \mathrm{O}_{2}$ demonstrated that the $z w f 1$ deletion carrying an empty vector was highly sensitive (Fig. 7). This sensitivity was not only rescued by the native Zwf1 but also to a considerable extent by the plant enzyme GapN. This result indicates that GapN from plants can generate sufficient NADPH to mediate resistance against oxidative stress conditions even in yeast cells. The weaker suppression of the oxidative stress sensitivity by GapN as compared to the complementation capacity of the native Zwf1 could be attributed to two lines of reasoning: i) the native $Z W F 1$ gene expressed under the control of the yeast $P F K 2$ promoter generates an enzyme with a specific G6PDH activity of $303 \pm 10 \mathrm{mU} / \mathrm{mg}$ protein. On the other hand, specific GapN activity only amounted to 10 $\pm 2 \mathrm{mU} / \mathrm{mg}$ protein, which is near the limitof detection in the assay used and may thus generate much less NADPH than the Zwf1 reaction. ii) Since GapN activity is not present in normal yeast cells, diversion of the flux from the NADH-generating glycolytic reaction of the yeast's GAPDH isoforms may interfere with the yeast's metabolism and lead to a reduced capacity of antioxidant defense. Nevertheless, the increased resistance of the transformants with GapN activity as compared to those with the vector control clearly demonstrates its ability to generate sufficient NADPH in yeast to suppress some of the negative effects of $\mathrm{H}_{2} \mathrm{O}_{2}$ exposure.

\section{Discussion}

We here demonstrate evidence that the GapC isoforms of Arabidopsis thaliana localize to different cellular compartments depending on their oxidation state. This may be related to moonlighting functions apart from the catalysis of the glycolytic reaction. Thus, active glycolytic metabolons have been suggested to form in the vicinity of the mitochondrial surface. When the redox-state of the cell starts to be shifted into oxidizing conditions upon stress, a portion of the redox-sensitive GapC will be oxidized and can translocate into the nucleus, where it possibly initiates a changed gene expression.

Association of $\mathrm{GapC}$ with the outer membrane of plant mitochondria had been shown previously $[9,50,51]$. We observed an enhanced colocalization of GapC1 with mitochondria under reducing conditions when cells are in a metabolically active state compared to oxidizing conditions. This indicates the formation of metabolons by which glycolysis is directly taking place in proximity to mitochondria. Such metabolons are built of glycolytic enzymes, channeling the intermediates efficiently through the pathway and enabling import of the products into mitochondria for further oxidation in the respiratory chain. VDAC might serve as a docking platform for such metabolons. The present in vitro interaction study revealed that reduced GapC exhibits a higher affinity for VDAC compared to the oxidized GapC. In fact, this supports the hypothesis that reduced GapC forms an active glycolytic metabolon attached to the OMM via VDAC3.

In colocalization experiments presented here, GapC was found to accumulate in the nucleus upon oxidative stress. Furthermore, GapC had been detected in nuclei of cadmium-treated roots [10], and in calcium- and NO-stressed tobacco BY-2 cells [11]. There is now a growing number of publications describing the "moonlighting" functions of GAPDH in the nucleus $[2,3,5$, 16]. As a well-studied example in the mammalian system, an association of $S$-nitrosylated GAPDH and SIAH1, an E3-ubiquitin ligase, leads to nuclear translocation and induction of cell death [60]. In fact, a 


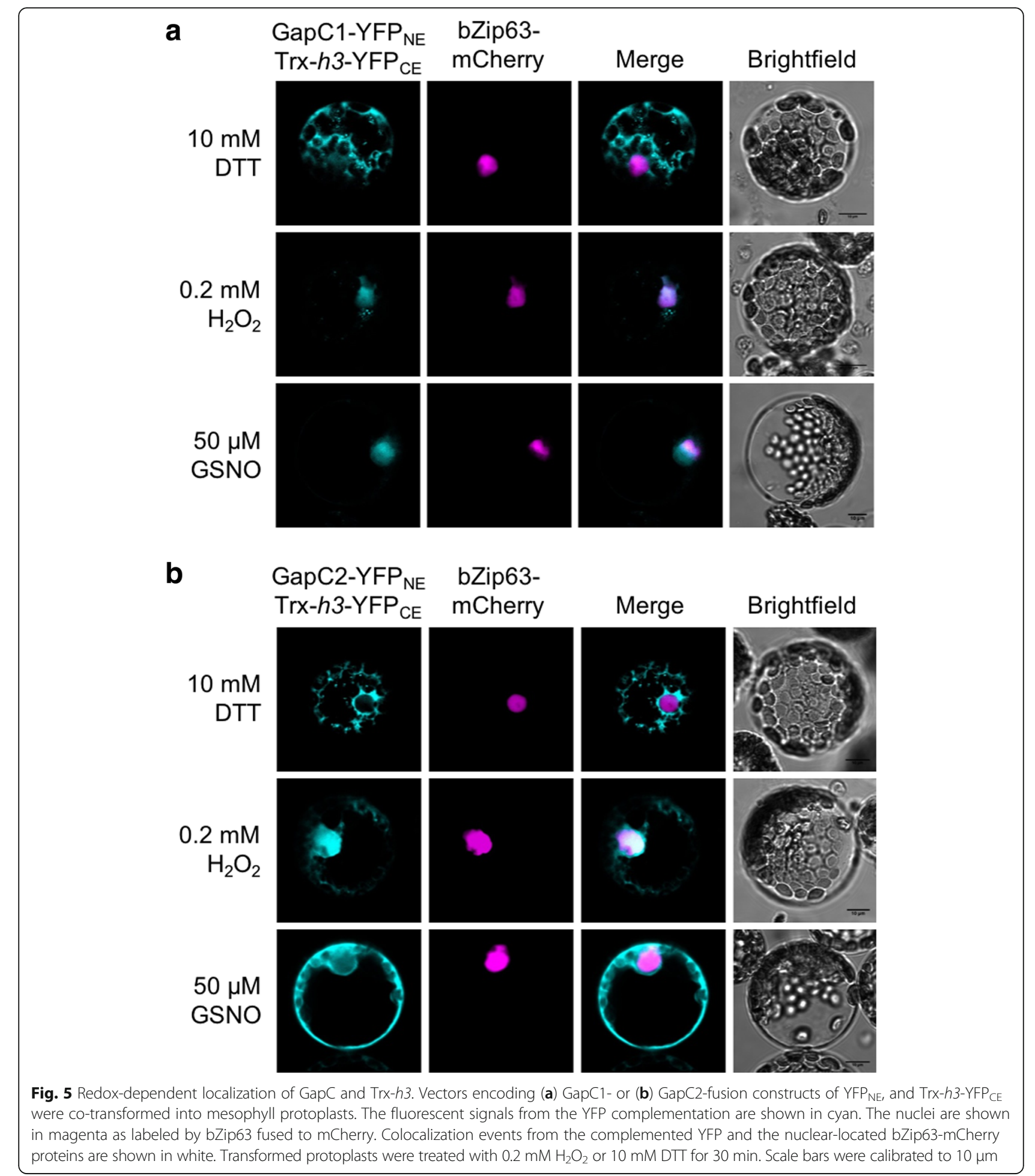

similar protein, namely SINAL7, was identified as a binding partner of GapC in plants [61]. In rice, GapC was found to be responsible for transcriptional activation of glycolytic genes under oxidative stress [62].

In various Trx-interaction studies, GapC had been found as a target protein $[27,52]$. Due to the transient nature of the nuclear localization, the interaction with a redox-mediating compound such as Trx must be assumed for the reversal of the cysteine modifications. Trx type- $h$ was found in the nucleus of oxidatively stressed Arabidopsis cells $[63,64]$. It had been suggested that denitrosylation of modified proteins in animal cells is 


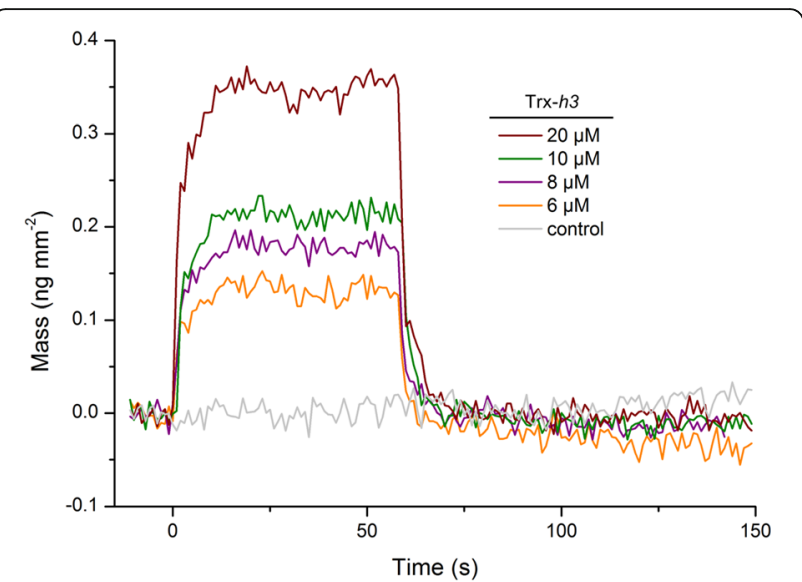

Fig. 6 Binding of Trx-h3 to GapC1. Binding kinetics of Trx-h3 to immobilized GapC1 were monitored by Rlf spectroscopy. The experiment was performed in $20 \mathrm{mM} \mathrm{HBS}$-buffer $(100 \mathrm{mM} \mathrm{NaCl}$, $0.01 \%$ Triton X-100, pH 7.5) supplemented with $2 \mathrm{mM}$ DTT. The GapC1 protein was immobilized via NHS. Association and dissociation reactions were recorded at different $T r x-h 3$ concentrations

catalyzed by the thioredoxin system [65]. In Chlamydomonas, cytosolic Trx- $h$ isoforms even seem to possess some specificity of their nuclear functions in response to different types of DNA damage [64]. If GapC fulfills a moonlighting function by regulation of nuclear gene expression, interaction with Trx- $h 3$ could be interpreted in view of the reversal of the oxidative modification and concomitant export from the nucleus, thus aborting its access to the transcription machinery after a stress period.

As soon as any disturbance of the metabolic flux becomes evident, $\mathrm{H}_{2} \mathrm{O}_{2}$ or $\mathrm{NO}$ is formed leading to modifications of the most sensitive thiols of GAPDH [13, 66], triose-phosphate isomerase [67] or pyruvate kinase M2 [68]. These examples demonstrate that the central glycolytic pathway is flexibly adjusted by linking the cellular redox-state and the substrate pool sizes at multiple steps. Due to the concomitant inactivation upon oxidative stress, glucose oxidation is redirected towards the OPP for NADPH generation by G6PDH [69]. Alternatively, the oxidation of GAP via GapN is an additional source for NADPH in plants, especially under increasing oxidant levels [54] (Fig. 8).

Due to its redox-sensitive catalytic cysteine, GapC provides a connection of redox-state and energy metabolism $[13,16]$. Therefore, GapC might serve as a central hub for energy supply and signal transfer to execute the various cellular fates [70, 71]. Redox-dependent processes are now accepted as major players in a multitude of cellular processes, and as important signal transmitters to induce readjustment of homeostasis upon oxidative stress [72]. Various sources, duration, and levels of stress can be transmitted by a specific post-translational modification code that is highly dynamic. Stress stimuli could lead to a differential modification pattern on a single protein. The idea of a modification code combining modifications also of other residues with the various redox-modifications of cysteine is tempting. Obviously, such a code can only be investigated and deciphered in vivo. Yet, only a minor proportion of each protein in question is expected to be modified for triggering the specific response. To solve this problem, high-resolution analysis of all single GAPDH molecules would be required to identify different modification patterns in subfractions of the cellular GAPDH pool.

An equally challenging task is the exact determination of the stimuli that provoke each modification, resulting in a complex interplay of different factors in vivo, and different output in each case. These modifications are additionally dependent on metabolites, microenvironmental conditions and/or macromolecular crowding effects [73, 74]. To prove any effect in such a complex scenario in vivo and to mimick a realistic microenvironment in vitro, will be a

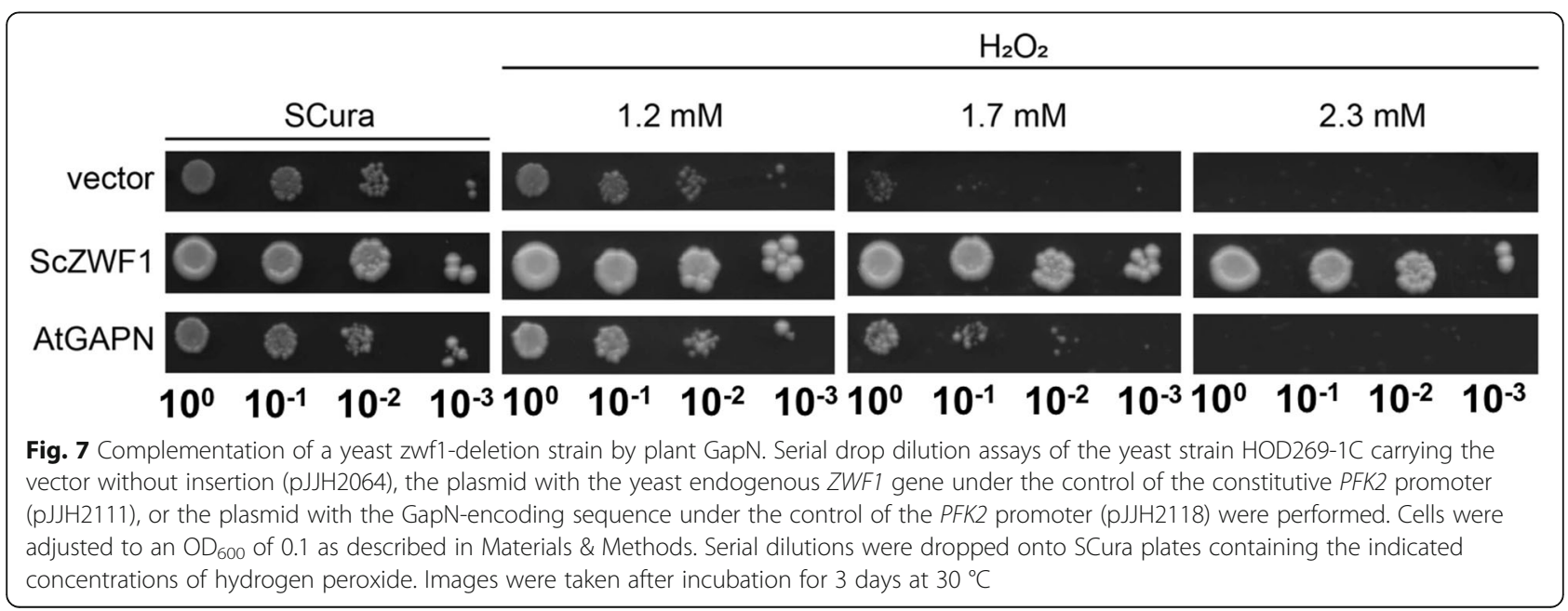




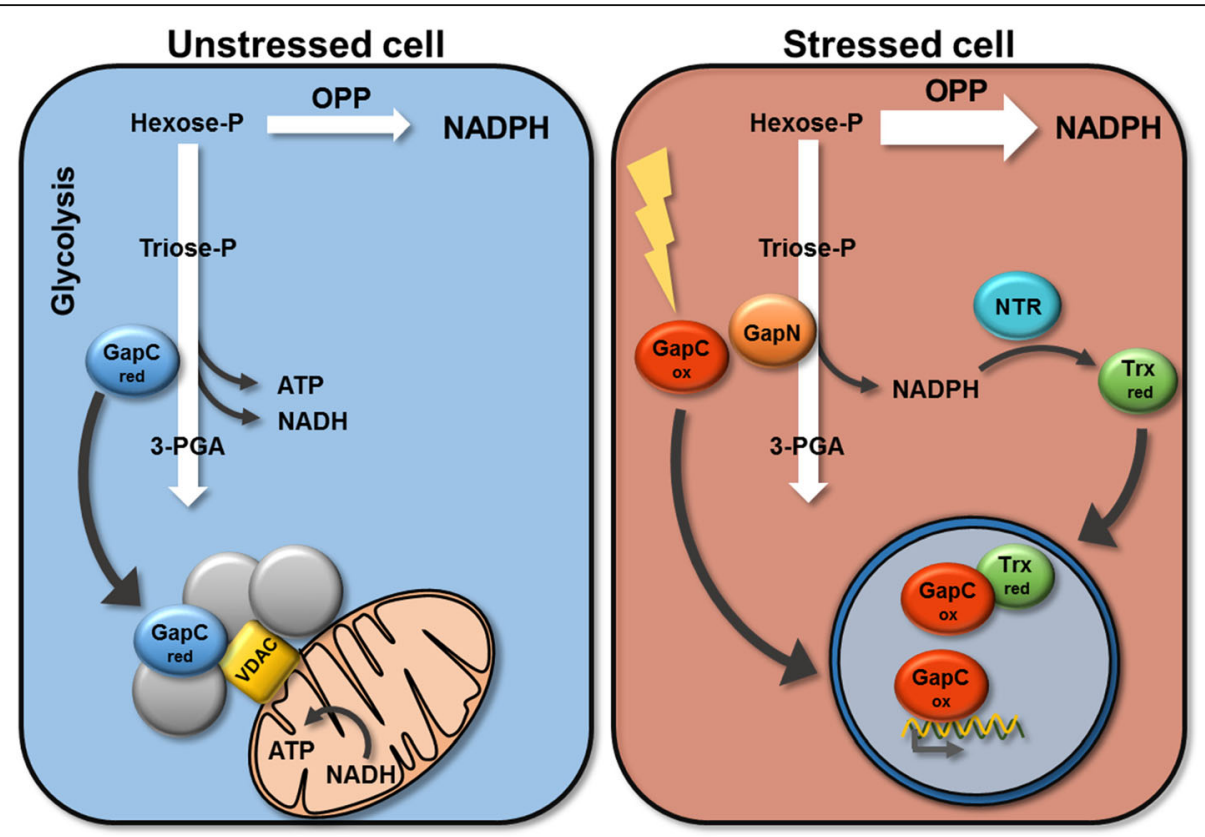

Fig. 8 Pathways of carbohydrate oxidation. In unstressed cells (left panel), glycolysis and respiration are reinforced by the formation of a metabolon at the mitochondria attached to VDAC. In a stressed cell (right panel), GapC serves as a redox-sensor and mediates signal transfer to the nucleus, where genes required for poising and ROS defense are induced. NADPH is provided by GapN, specific for plants. In both cases, NADPH can also be provided by the OPP

difficult task for the future. The investigation of the switching ability between GAPDH activity in the central metabolism and its role as a redox-sensor by classical genetic methods carries the intrinsic problem that these functions are both dependent upon the active-site cysteine of the protein. GAPDH-knockout mutants show many pleiotropic effects which are not distinguishable in relation to their origin due to the dual role of the active-site cysteine. Any effects could be either caused by the lack of the moonlighting functions of GAPDH or an impeded central metabolism when glycolysis is not functional.

\section{Conclusions}

The glycolytic enzyme GapC is a versatile hub to sense and counteract metabolic and redox imbalances. Both pieces of information are integrated into signaling pathways for a proper response. Many different input signals evoke multiple cellular responses, ranging from improved growth to induction of programmed cell death (PCD). In particular in plants, integration of signals from environmental impact and developmental state in the various photoautotrophic and heterotrophic tissues requires effective regulatory systems that respond accordingly to maintain homeostasis [75]. The occurrence of $S$-glutathionylation, $S$-sulfhydration, and/or $S$-nitrosylation at the catalytic cysteine and/or the neighboring cysteine of GAPDH could serve as a redox code [76]. The degree and kind of stress might even be reflected in a specific pattern of the various possible modifications of sensitive cysteines, thus transferring the actual information in a finely graduated way to obtain the proper output. Based on such a system, a wide spectrum of environmental challenges and metabolic imbalances can be responded to at the various levels of regulation to regain and maintain homeostasis. In the worst case, execution of PCD to prevent further ROS formation in damaged cells, when metabolism gets out of control, might then be also an appropriate response.

A transient inactivation of GAPDH suggests that the glycolytic pathway will be down-regulated during oxidative or nitrosative stress. For the time of imbalance, this leads to a redirection of the metabolic flux away from glycolysis and ATP production into the OPP pathway for rapid generation of NADPH required for GSSG reduction poising, and repair [69]. Additionally, apart from the oxidation of G6P through the activity of G6PDH, the required NADPH can be provided by oxidation of triose-P through the cytosolic GapN. Ectopic expression of GapN enables the yeast strain lacking G6PDH to persist oxidative stress conditions by its capability to provide NADPH (Fig. 8).

On the other hand, oxidative modifications affect the binding properties of GapC and its subcellular localization. Due to the various post-translational modifications, transient formation of subcompartments or metabolons, changing cellular localizations and moonlighting functions can 
be initiated [77]. Upon regain of homeostasis, signals need to be converted back to normal, and regular energy metabolism should recover. This requires the reversal of GapC modifications and ending of its moonlighting functions. Here, the NADPH-generating systems for regeneration of reduced thioredoxins and reversal of cysteine modifications are also required.

In the present study, we could demonstrate the redox-dependence of the cellular localization of GapC, resulting in increased nuclear localization of both isoforms under oxidizing conditions, and the interaction with Trx- $h 3$ in the nucleus. Binding of GapC isoforms to the mitochondrial VDAC, on the other hand, was more pronounced under reducing conditions as would be the case upon recovery. The efficiency of the glycolytic flux is then optimized by the formation of a metabolon in close vicinity of the mitochondria.

\section{Additional files}

Additional file 1: Table S1. Primer used for the amplification of the ZWF1 gene encoding the glucose-6-phosphate dehydrogenase. Primer sequences used to generate the different yeast strains for the yeast complementation assay. (DOCX $14 \mathrm{~kb}$ )

Additional file 2: Figure S1. Redox-dependent binding of GapC1 to VDAC3. Binding kinetics of the GapC1-VDAC3 interaction were monitored by Rlf spectroscopy. (A) After the injection of VDAC3-containing proteoliposomes (gray), the formation of a polymer-supported membrane and the binding of GapC1 to VDAC3 (light blue) were recorded by labelfree Rlf detection. (B) Representative association and dissociation behavior of reduced and oxidized GapC1 and VDAC3 with the respective residuals. (PPTX $169 \mathrm{~kb}$ )

Additional file 3: Figure S2. Determination of the $K_{D}$ for the interaction of GapC1 with Trx-h3. The values of the equilibrium binding signals ( $\left.\Gamma_{\mathrm{eq}}\right)$ for each experiment were plotted against the ratio of the binding signal to the concentration of $\operatorname{Trx}-h 3\left(\Gamma_{\mathrm{eq}} / \mathrm{c}\right)$. The $K_{D}$ value of the corresponding interaction of Trx-h3 with GapC1 was extracted from the slope of the corresponding. (PPTX $50 \mathrm{~kb}$ )

\section{Acknowledgments}

We would like to thank Minhee Kang for performing initial experiments. Provision of the E. coli BL21 (DE3)-omp9 strain from Prof. Dr. Lars-Oliver Essen (Philipps-Universität, Marburg, Germany) is acknowledged. We thank the Department of Biophysics for access to their Rlf facilities, and Andrea Murra for technical assistance.

\section{Funding}

Our research was funded by the German research foundation (DFG) within the Collaborative Research Centre (CRC) 944 "Physiology and dynamics of cellular micro-compartments".

\section{Availability of data and materials}

Data and materials are available from the authors upon request.

\section{Authors' contributions}

$\mathrm{MS}, \mathrm{JK}$ and $\mathrm{JJH}$ performed the experiments. MS, JK, and JJH analyzed the data. OB helped with RIf data evaluation. MS, JK, JJH and RS designed the project and wrote the article.

\section{Ethics approval and consent to participate} Not applicable.
Consent for publication

Not applicable.

\section{Competing interests}

The authors declare that they have no competing interests.

\section{Publisher's Note}

Springer Nature remains neutral with regard to jurisdictional claims in published maps and institutional affiliations.

\section{Author details}

'Division of Plant Physiology, Department of Biology and Chemistry, Osnabrück University, Barbarastr. 11, 49076 Osnabrück, Germany. ${ }^{2}$ Division of Biophysics, Department of Biology and Chemistry, Osnabrück University, Barbarastr. 11, 49076 Osnabrück, Germany. ${ }^{3}$ Division of Genetics, Department of Biology and Chemistry, Osnabrück University, Barbarastr. 11, 49076 Osnabrück, Germany.

Received: 18 October 2017 Accepted: 22 August 2018

Published online: 06 September 2018

\section{References}

1. Scheibe R, Dietz K-J. Reduction-oxidation network for flexible adjustment of cellular metabolism in photoautotrophic cells. Plant Cell Environ. 2012;35: 202-16. https://doi.org/10.1111/j.1365-3040.2011.02319.x.

2. Sirover MA. Subcellular dynamics of multifunctional protein regulation: mechanisms of GAPDH intracellular translocation. J Cell Biochem. 2012;113: 2193-200. https://doi.org/10.1002/jcb.24113.

3. Tristan C, Shahani N, Sedlak TW, Sawa A. The diverse functions of GAPDH: views from different subcellular compartments. Cell Signal. 2011;23:317-23. https://doi.org/10.1016/j.cellsig.2010.08.003.

4. Zaffagnini M, Fermani S, Costa A, Lemaire SD, Trost P. Plant cytoplasmic GAPDH: redox post-translational modifications and moonlighting properties. Front Plant Sci. 2013:4:450. https://doi.org/10.3389/fpls.2013.00450.

5. Nicholls C, Li H, Liu J-P. GAPDH: a common enzyme with uncommon functions. Clin Exp Pharmacol Physiol. 2012;39:674-9. https://doi.org/10. 1111/j.1440-1681.2011.05599.x.

6. White MR. Garcin ED. D-glyceraldehyde-3-phosphate dehydrogenase structure and function. Subcell Biochem. 2017:83:413-53. https://doi.org/10. 1007/978-3-319-46503-6_15.

7. Holtgrefe S, Gohlke J, Starmann J, Druce S, Klocke S, Altmann B, et al. Regulation of plant cytosolic glyceraldehyde 3-phosphate dehydrogenase isoforms by thiol modifications. Physiol Plant. 2008;133:211-28. https://doi. org/10.1111/j.1399-3054.2008.01066.x.

8. Holtgräwe D, Scholz A, Altmann B, Scheibe R. Cytoskeleton-associated, carbohydrate-metabolizing enzymes in maize identified by yeast two-hybrid screening. Physiol Plant. 2005;125:141-56. https://doi.org/10.1111/j.13993054.2005.00548.x

9. Wojtera-Kwiczor J, Groß F, Leffers H-M, Kang M, Schneider M, Scheibe R. Transfer of a redox-signal through the cytosol by redox-dependent microcompartmentation of glycolytic enzymes at mitochondria and actin cytoskeleton. Front Plant Sci. 2012;3:284. https://doi.org/10.3389/fpls.2012. 00284.

10. Vescovi M, Zaffagnini M, Festa M, Trost P, Lo Schiavo F, Costa A. Nuclear accumulation of cytosolic glyceraldehyde-3-phosphate dehydrogenase in cadmium-stressed Arabidopsis roots. Plant Physiol. 2013;162:333-46. https:// doi.org/10.1104/pp.113.215194.

11. Testard A, Da Silva D, Ormancey M, Pichereaux C, Pouzet C, Jauneau A, et al, Calcium- and nitric oxide-dependent nuclear accumulation of cytosolic glyceraldehyde-3-phosphate dehydrogenase in response to long chain bases in tobacco BY-2 cells. Plant Cell Physiol. 2016;57:2221-31. https://doi. org/10.1093/pcp/pcw137.

12. Aroca A, Schneider M, Scheibe R, Gotor C, Romero LC. Hydrogen sulfide regulates the cytosolic/nuclear partitioning of glyceraldehyde-3phosphate dehydrogenase by enhancing its nuclear localization. Plant Cell Physiol. 2017;58:983-92. https://doi.org/10.1093/pcp/pcx056.

13. Peralta D, Bronowska AK, Morgan B, Dóka É, van Laer K, Nagy P, et al. A proton relay enhances $\mathrm{H}_{2} \mathrm{O} 2$ sensitivity of GAPDH to facilitate metabolic adaptation. Nat Chem Biol. 2015;11:156-63. https://doi.org/10.1038/ nchembio.1720. 
14. Zaffagnini M, Fermani S, Calvaresi M, Orrù R, lommarini L, Sparla F, et al. Tuning cysteine reactivity and sulfenic acidsStability by protein microenvironment in glyceraldehyde-3-phosphate dehydrogenases of Arabidopsis thaliana. Antioxid Redox Signal. 2016;24:502-17. https://doi.org/ 10.1089/ars.2015.6417.

15. Yang SS, Zhai QH. Cytosolic GAPDH: a key mediator in redox signal transduction in plants. Biol Plant. 2017;61:417-26. https://doi.org/10.1007/ s10535-017-0706-y.

16. Hildebrandt T, Knuesting J, Berndt C, Morgan B, Scheibe R. Cytosolic thiol switches regulating basic cellular functions: GAPDH as an information hub? Biol Chem. 2015;396:523-37. https://doi.org/10.1515/hsz-2014-0295.

17. Lindermayr C, Saalbach G, Durner J. Proteomic identification of Snitrosylated proteins in Arabidopsis. Plant Physiol. 2005;137:921-30. https:// doi.org/10.1104/pp.104.058719.

18. Dixon DP, Skipsey M, Grundy NM, Edwards R. Stress-induced protein Sglutathionylation in Arabidopsis. Plant Physiol. 2005;138:2233-44. https://doi. org/10.1104/pp.104.058917.

19. Dalle-Donne I, Rossi R, Colombo G, Giustarini D, Milzani A. Protein Sglutathionylation: a regulatory device from bacteria to humans. Trends Biochem Sci. 2009;34:85-96. https://doi.org/10.1016/j.tibs.2008.11.002.

20. Gould N, Doulias P-T, Tenopoulou M, Raju K, Ischiropoulos H. Regulation of protein function and signaling by reversible cysteine S-nitrosylation. J Biol Chem. 2013;288:26473-9. https://doi.org/10.1074/jbc.R113.460261.

21. Hancock JT, Henson D, Nyirenda M, Desikan R, Harrison J, Lewis M, et al. Proteomic identification of glyceraldehyde 3-phosphate dehydrogenase as an inhibitory target of hydrogen peroxide in Arabidopsis. Plant Physiol Biochem. 2005:43:828-35. https://doi.org/10.1016/j.plaphy.2005.07.012.

22. Gelhaye $\mathrm{E}$, Rouhier $\mathrm{N}$, Jacquot J-P. The thioredoxin h system of higher plants. Plant Physiol Biochem. 2004;42:265-71. https://doi.org/10.1016/j. plaphy.2004.03.002.

23. Delorme-Hinoux V, Bangash SAK, Meyer AJ, Reichheld J-P. Nuclear thiol redox systems in plants. Plant Sci. 2016;243:84-95. https://doi.org/10.1016/j. plantsci.2015.12.002

24. Bustos DM, Bustamante CA, Iglesias AA. Involvement of non-phosphorylating glyceraldehyde-3-phosphate dehydrogenase in response to oxidative stress. J Plant Physiol. 2008;165:456-61. https://doi.org/10.1016/j.jplph.2007.06.005.

25. Colombini M. Structure and mode of action of a voltage dependent anionselective channel (VDAC) located in the outer mitochondrial membrane. Ann N Y Acad Sci. 1980;341:552-63.

26. Colombini M. Mitochondrial outer membrane channels. Chem Rev. 2012; 112:6373-87. https://doi.org/10.1021/cr3002033.

27. Wong JH, Cai N, Balmer Y, Tanaka CK, Vensel WH, Hurkman WJ, Buchanan BB. Thioredoxin targets of developing wheat seeds identified by complementary proteomic approaches. Phytochemistry. 2004;65:1629-40. https://doi.org/10.1016/j.phytochem.2004.05.010.

28. Seidel T, Kluge C, Hanitzsch M, Ross J, Sauer M, Dietz K-J, Golldack D. Colocalization and FRET-analysis of subunits $\mathrm{c}$ and $\mathrm{a}$ of the vacuolar $\mathrm{H}+$-ATPase in living plant cells. J Biotechnol. 2004;112:165-75. https://doi.org/10.1016/j.jbiotec.2004.04.027.

29. Voss I, Koelmann M, Wojtera J, Holtgrefe S, Kitzmann C, Backhausen JE, Scheibe R. Knockout of major leaf ferredoxin reveals new redox-regulatory adaptations in Arabidopsis thaliana. Physiol Plant. 2008;133:584-98. https:// doi.org/10.1111/j.1399-3054.2008.01112.x.

30. Walter M, Chaban C, Schütze K, Batistic O, Weckermann K, Näke C, et al. Visualization of protein interactions in living plant cells using bimolecular fluorescence complementation. Plant J. 2004;40:428-38. https://doi.org/10. 1111/j.1365-313X.2004.02219.x.

31. Schindelin J, Arganda-Carreras I, Frise E, Kaynig V, Longair M, Pietzsch T, et al. Fiji: an open-source platform for biological-image analysis. Nat Methods. 2012;9:676-82. https://doi.org/10.1038/nmeth.2019.

32. Mertins B, Psakis G, Grosse W, Back KC, Salisowski A, Reiss P, et al. Flexibility of the N-terminal mVDAC1 segment controls the channel's gating behavior PLoS One. 2012;7:e47938. https://doi.org/10.1371/journal.pone.0047938.

33. Hiller S, Garces RG, Malia TJ, Orekhov VY, Colombini M, Wagner G. Solution structure of the integral human membrane protein VDAC-1 in detergent micelles. Science. 2008;321:1206-10. https://doi.org/10.1126/science.1161302.

34. Qing G, Ma L-C, Khorchid A, Swapna GVT, Mal TK, Takayama MM, et al. Cold-shock induced high-yield protein production in Escherichia coli. Nat Biotechnol. 2004;22:877-82. https://doi.org/10.1038/nbt984.

35. Prilipov A, Phale PS, van Gelder P, Rosenbusch JP, Koebnik R. Coupling sitedirected mutagenesis with high-level expression: large scale production of mutant porins from E. coli. FEMS Microbiol Lett. 1998;163:65-72.
36. Prilipov A, Phale PS, Koebnik R, Widmer C, Rosenbusch JP. Identification and characterization of two quiescent porin genes, $\mathrm{nmpC}$ and ompN, in Escherichia coli BE. J Bacteriol. 1998;180:3388-92.

37. Degrip WJ, Vanoostrum J, Bovee-Geurts PH. Selective detergent-extraction from mixed detergent/lipid/protein micelles, using cyclodextrin inclusion compounds: a novel generic approach for the preparation of proteoliposomes. Biochem J. 1998;330(Pt 2):667-74.

38. Roder F, Birkholz O, Beutel O, Paterok D, Piehler J. Spatial organization of lipid phases in micropatterned polymer-supported membranes. J Am Chem Soc. 2013;135:1189-92. https://doi.org/10.1021/ja310186g.

39. Peel MJ, Cross SJ, Birkholz O, Aladağ A, Piehler J, Peel S. Rupture of stochastically occurring vesicle clusters limits bilayer formation on alkane-PEG-type supports: uncoupling clustering from surface coverage. Langmuir. 2015;31:8830-40. https:// doi.org/10.1021/acs.langmuir.5b00925.

40. Gavutis M, Lata S, Lamken P, Müller P, Piehler J. Lateral ligand-receptor interactions on membranes probed by simultaneous fluorescenceinterference detection. Biophys J. 2005;88:4289-302. https://doi.org/10.1529/ biophysj.104.055855

41. Piehler J, Brecht A, Valiokas R, Liedberg B, Gauglitz G. A high-density poly (ethylene glycol) polymer brush for immobilization on glass-type surfaces. Biosens Bioelectron. 2000;15:473-81. https://doi.org/10.1016/S09565663(00)00104-4.

42. Kirchrath L, Lorberg A, Schmitz HP, Gengenbacher U, Heinisch JJ. Comparative genetic and physiological studies of the MAP kinase Mpk1p from Kluyveromyces lactis and Saccharomyces cerevisiae. J Mol Biol. 2000;300: 743-58. https://doi.org/10.1006/jmbi.2000.3916.

43. Gueldener U, Heinisch J, Koehler GJ, Voss D, Hegemann JH. A second set of loxP marker cassettes for Cre-mediated multiple gene knockouts in budding yeast. Nucleic Acids Res. 2002;30:e23.

44. Arvanitidis A, Heinisch JJ. Studies on the function of yeast phosphofructokinase subunits by in vitro mutagenesis. J Biol Chem. 1994;269:8911-8.

45. Myers AM, Tzagoloff A, Kinney DM, Lusty CJ. Yeast shuttle and integrative vectors with multiple cloning sites suitable for construction of lacZ fusions. Gene. 1986:45:299-310.

46. Heinisch J, Vogelsang K, Hollenberg CP. Transcriptional control of yeast phosphofructokinase gene expression. FEBS Lett. 1991;289:77-82.

47. Sherman F, Fink G, Hicks J. Methods in Yeast Genetics: A Laboratory Course Manual. Cold Spring Harbor Laboratory Press. 1987;180:ISBN 9780879691974.

48. Rodicio R, Koch S, Schmitz H-P, Heinisch JJ. KIRHO1 and KIPKC1 are essential for cell integrity signalling in Kluyveromyces lactis. Microbiology. 2006;152: 2635-49. https://doi.org/10.1099/mic.0.29105-0..

49. Zamenhof S. [103] Preparation and assay of deoxyribonucleic acid from animal tissue. In: Methods of Enzymology, Vol. 3, Elsevier; 1957. pp. 696-704. doi:https://doi.org/10.1016/S0076-6879(57)03446-1.

50. Graham JWA, Williams TCR, Morgan M, Fernie AR, Ratcliffe RG, Sweetlove LJ. Glycolytic enzymes associate dynamically with mitochondria in response to respiratory demand and support substrate channeling. Plant Cell. 2007;19: 3723-38. https://doi.org/10.1105/tpc.107.053371.

51. Giegé P, Heazlewood JL, Roessner-Tunali U, Millar AH, Fernie AR, Leaver CJ, Sweetlove $L$. Enzymes of glycolysis are functionally associated with the mitochondrion in Arabidopsis cells. Plant Cell. 2003;15:2140-51. https://doi. org/10.1105/tpc.012500.

52. Yamazaki D, Motohashi K, Kasama T, Hara Y, Hisabori T. Target proteins of the cytosolic thioredoxins in Arabidopsis thaliana. Plant Cell Physiol. 2004;45: 18-27. https://doi.org/10.1093/pcp/pch019.

53. Bedhomme M, Adamo M, Marchand CH, Couturier J, Rouhier N, Lemaire SD, et al. Glutathionylation of cytosolic glyceraldehyde-3-phosphate dehydrogenase from the model plant Arabidopsis thaliana is reversed by both glutaredoxins and thioredoxins in vitro. Biochem J. 2012;445:337-47. https://doi.org/10.1042/ BJ20120505.

54. Piattoni CV, Guerrero SA, Iglesias AA. A differential redox regulation of the pathways metabolizing glyceraldehyde-3-phosphate tunes the production of reducing power in the cytosol of plant cells. Int J Mol Sci. 2013;14:807392. https://doi.org/10.3390/ijms14048073.

55. Wakao S, Benning C. Genome-wide analysis of glucose-6-phosphate dehydrogenases in Arabidopsis. Plant J. 2005;41:243-56. https://doi.org/10. 1111/j.1365-313X.2004.02293.X.

56. Iddar A, Valverde F, Serrano A, Soukri A. Purification of recombinant non-phosphorylating NADP-dependent glyceraldehyde-3-phosphate dehydrogenase from Streptococcus pyogenes expressed in E. coli. Mol Cell Biochem. 2003;247:195-203. 
57. Nogae I, Johnston M. Isolation and characterization of the ZWF1 gene of Saccharomyces cerevisiae, encoding glucose-6-phosphate dehydrogenase. Gene. 1990;96:161-9. https://doi.org/10.1016/0378-1119(90)90248-P.

58. Schaaff-Gerstenschläger I, Zimmermann FK. Pentose-phosphate pathway in Saccharomyces cerevisiae: analysis of deletion mutants for transketolase, transaldolase, and glucose 6-phosphate dehydrogenase. Curr Genet. 1993; 24:373-6.

59. Raben N, Exelbert R, Spiegel R, Sherman JB, Nakajima H, Plotz P, Heinisch J. Functional expression of human mutant phosphofructokinase in yeast: genetic defects in French Canadian and Swiss patients with phosphofructokinase deficiency. Am J Hum Genet. 1995;56:131-41.

60. Hara MR, Agrawal N, Kim SF, Cascio MB, Fujimuro M, Ozeki Y, et al. Snitrosylated GAPDH initiates apoptotic cell death by nuclear translocation following Siah1 binding. Nat Cell Biol. 2005;7:665-74. https://doi.org/10. 1038/ncb1268.

61. Peralta DA, Araya A, Busi MV, Gomez-Casati DF. The E3 ubiquitin-ligase SEVEN IN ABSENTIA like 7 mono-ubiquitinates glyceraldehyde-3-phosphate dehydrogenase 1 isoform in vitro and is required for its nuclear localization in Arabidopsis thaliana. Int J Biochem Cell Biol. 2016;70:48-56. https://doi. org/10.1016/j.biocel.2015.11.007.

62. Zhang $H$, Zhao Y, Zhou D-X. Rice NAD ${ }^{+}$-dependent histone deacetylase OsSRT1 represses glycolysis and regulates the moonlighting function of GAPDH as a transcriptional activator of glycolytic genes. Nucleic Acids Res. 2017; https://doi.org/10.1093/nar/gkx825.

63. Serrato AJ, Cejudo FJ. Type-h thioredoxins accumulate in the nucleus of developing wheat seed tissues suffering oxidative stress. Planta. 2003;217: 392-9. https://doi.org/10.1007/s00425-003-1009-4.

64. Sarkar N, Lemaire S, Wu-Scharf D, Issakidis-Bourguet E, Cerutti H. Functional specialization of Chlamydomonas reinhardtii cytosolic thioredoxin $\mathrm{h} 1 \mathrm{in}$ the response to alkylation-induced DNA damage. Eukaryot Cell. 2005;4:262-73. https://doi.org/10.1128/EC.4.2.262-273.2005.

65. Benhar M, Forrester MT, Stamler JS. Protein denitrosylation: enzymatic mechanisms and cellular functions. Nat Rev Mol Cell Biol. 2009;10:721-32. https://doi.org/10.1038/nrm2764.

66. Hancock J, Desikan R, Harrison J, Bright J, Hooley R, Neill S. Doing the unexpected: proteins involved in hydrogen peroxide perception. J Exp Bot. 2006:57:1711-8. https://doi.org/10.1093/jxb/erj180.

67. Dumont S, Bykova NV, Pelletier G, Dorion S, Rivoal J. Cytosolic triosephosphate isomerase from Arabidopsis thaliana is reversibly modified by glutathione on cysteines 127 and 218. Front Plant Sci. 2016;7:1942. https://doi.org/10.3389/fpls.2016.01942.

68. Anastasiou D, Poulogiannis G, Asara JM, Boxer MB, Jiang J-K, Shen M, et al. Inhibition of pyruvate kinase $\mathrm{M} 2$ by reactive oxygen species contributes to cellular antioxidant responses. Science. 2011;334:1278-83. https://doi.org/10. 1126/science.1211485.

69. Ralser M, Wamelink MM, Kowald A, Gerisch B, Heeren G, Struys EA, et al. Dynamic rerouting of the carbohydrate flux is key to counteracting oxidative stress. J Biol. 2007:6:10. https://doi.org/10.1186/jbiol61.

70. Quijano C, Trujillo M, Castro L, Trostchansky A. Interplay between oxidant species and energy metabolism. Redox Biol. 2016;8:28-42. https://doi.org/10 1016/j.redox.2015.11.010.

71. Boukouris AE, Zervopoulos SD, Michelakis ED. Metabolic enzymes moonlighting in the nucleus: metabolic regulation of gene transcription. Trends Biochem Sci. 2016;41:712-30. https://doi.org/10.1016/j.tibs.2016.05.013.

72. Foyer CH, Noctor G. Stress-triggered redox signalling: What's in pROSpect? Plant Cell Environ. 2016;39:951-64. https://doi.org/10.1111/pce.12621.

73. Menard L, Maughan D, Vigoreaux J. The structural and functional coordination of glycolytic enzymes in muscle: evidence of a metabolon? Biology. 2014;3:623-44. https://doi.org/10.3390/biology3030623.

74. Srere PA. Macromolecular interactions: tracing the roots. Trends Biochem Sci. 2000:25:150-3.

75. Scheibe R, Backhausen JE, Emmerlich V, Holtgrefe S. Strategies to maintain redox homeostasis during photosynthesis under changing conditions. J Exp Bot. 2005;56:1481-9. https://doi.org/10.1093/jxb/eri181.

76. Jones DP, Sies H. The redox code. Antioxid Redox Signal. 2015;23:734-46. https://doi.org/10.1089/ars.2015.6247.

77. Zachgo S, Hanke GT, Scheibe R. Plant cell microcompartments: a redoxsignaling perspective. Biol Chem. 2013;394:203-16. https://doi.org/10.1515/ hsz-2012-0284.

\section{Ready to submit your research? Choose BMC and benefit from:}

- fast, convenient online submission

- thorough peer review by experienced researchers in your field

- rapid publication on acceptance

- support for research data, including large and complex data types

- gold Open Access which fosters wider collaboration and increased citations

- maximum visibility for your research: over $100 \mathrm{M}$ website views per year

At $\mathrm{BMC}$, research is always in progress.

Learn more biomedcentral.com/submissions 